\title{
AN EVALUATION OF MULTI TIER APPROACH TOWARDS CAPACITY BUILDING AND INSTITUTIONAL STRENGTHENING THROUGH APPLICATION OF GEO SPATIAL TECHNOLOGY IN PURVIEW OF AMRUT SCHEME
}

\author{
Santanu Das ${ }^{1, *}$, P L N Raju ${ }^{1}$, Jenita M Nongkynrih ${ }^{1}$ \\ ${ }^{1}$ North eastern Space Applications Centre, Meghalaya, Indian - (santanudas.0906, plnraju, Jnongkynrih)@gmail.com
}

Commission V, WG V/1

KEY WORDS: Capacity Building, Multi Tier Approach, Urban Planning, Geo-spatial technology, AMRUT

\begin{abstract}
:
Many initiatives around the world are emphasising to strengthen the capacities of civil society and local governments to build resilience towards the context of urban planning. The Indian cities are experiencing rapid growth with share of country's urban population increasing from $27 \%$ in 2001 to $32 \%$ in 2011 . Majority of this growth has taken place in an unplanned and haphazard manner, the ill-effects of which are manifested in the form of poor quality of urban life. In order to ensure a planned development, the Govt. of India has launched the Atal Mission for Rejuvenation and Urban Transformation (AMRUT) Mission which has a subscheme on 'Formulation of GIS Based Master Plan for AMRUT cities'.

In order to Achieve these ambitions, and realising the potential for cities to contribute effectively to addressing the challenges of development, will require new skills and competencies towards technological advancements and their application within individual households, urban communities, formal civil society, and municipal governments. To this end, North Eastern Space Applications Centre (NESAC), Umiam, Meghalaya in association with Town \& Country Planning Organization, Ministry of Housing and Urban Affairs, Govt. of India, initiated the training programme on "Formulation of GIS Based Master Plans". The training programmes inculcates on the use of GIS and Remote sensing techniques for the formulation of Master Plans through a Tier based Approach with a vision to entrench existing relationships and to achieve more transformative change that meets the needs of all urban residents.
\end{abstract}

\section{INTRODUCTION}

\subsection{Need for the study}

Urbanization and urban planning need to act in a cohesive manner in order to address the progressive concentration of population in urban unit. On the contrary, Urban Local bodies are constantly facing extreme difficulties in order to plan for sustainable urban development and are confronted with a number of problems, such as data unavailability, ineffective participation in the decision-making process, delays in the transfer of funds to the urban local bodies despite constitution of State Finance Authorities, poor recovery from various tax and non-tax sources despite devolution of power and lack of trained human resource in the use of new technology of GIS, GPS and Remote Sensing. It is significant to upgrade and strengthen the capacity of multi level actors in the hierarchy having a distinct role in administering, managing and implementation of urban services for development of cities and towns.

On the other hand, the complexity of sustainable development defies the traditional approach towards capacity building and is adversely affecting the problem solving capabilities of local administration. Therefore, there is an urgent need to adopt modern technology of remote sensing which includes both aerial as well as satellite based systems, allow us to collect lot of physical data rather easily, with speed and on repetitive basis, and together with GIS helps us to analyze the data spatially, offering possibilities of generating various options (modeling), thereby optimizing the whole planning process. These information systems also offer interpretation of physical (spatial) data with other socio-economic data, and thereby provide an important linkage in the total planning process and making it more effective and meaningful.

North Eastern Space Applications Centre (NESAC), Umiam, Meghalaya in association with Town \& Country Planning Organization, Ministry of Housing and Urban Affairs, Govt. of India, initiated the training programme on "Formulation of GIS Based Master Plans". The training programmes include handson training on the use of GIS softwares including open source GIS/RS technologies, data-base generation and updation for the formulation of Master Plan.

\subsection{About AMRUT Scheme}

Formulation of GIS based master plan for 500 AMRUT cities is one of the most important reforms under Atal Mission for Rejuvenation and Urban Transformation envisaging the objective of developing High Resolution Geo-database at $1: 4000$ scale.

This calls in for a more integrative approach to an institutional and organizational environment conducive to and supportive of, their efforts, energies and capacities. Thus Building capacity among town planning, line departments and other concerned personnel at state and local levels including ULBs and

\footnotetext{
* Corresponding author
} 
development authorities to create a cadre of professionals proficient in the use of GIS technology for using and updating databases in urban planning and management.

\subsection{Target Group \& Approach}

Operators, technicians, draftsmen, planning assistants, town planners and administrators are trained during the program at different stages with regard to their role in implementing the scheme. The duration of the training imparted depends on the role of the personnel and has been divided into three levels. Tier 1: Decision Makers (3 days program), Tier 2: Middle Level Officers (2 weeks program) and Tier 3: Junior (Operator) Level Officers (4 weeks program).

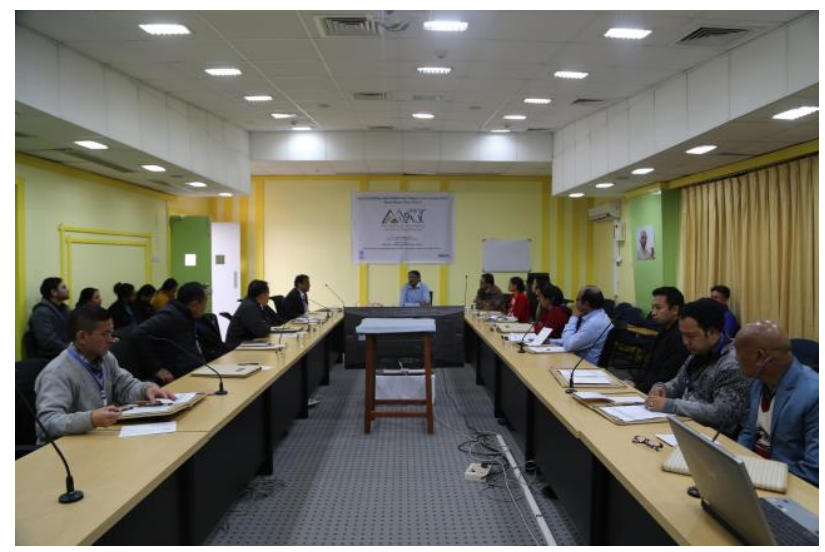

\subsection{Objectives}

This training was imparted with the objective to equip with the knowledge on the application of geospatial technology in master plan formulation. This training has been designed to provide sufficient knowledge for urban master planning purposes with regard to their role in implementing the scheme.

The present paper presents an example of a multi level human resource development through knowledge dissemination, comprising of decision makers, managers, professionals and technicians. The research work assesses institutional capacitybuilding, pedagogy systems and sustainable learning thereby increasing substantial knowledge and eradicating Institutional and organizational constraints towards implementation of the AMRUT scheme leading to effective management of cities and settlements.

\section{METHODOLOGY}

\subsection{Designing the Course Content}

The content of the programme included lectures on application of tools and techniques such as Government Initiatives in Geospatial Technology based Planning, Overview of Remote Sensing and Geographic Information System, Survey Techniques, Navigation Systems and Advances in Geospatial Technologies, Digital Image processing, Map projections and Mobile Apps and their usability in urban planning, GIS Analysis \& Modelling, Applications of Unmanned Aerial Vehicles (Drones), Ground penetrating Radar and their applicability in preparation of an effective master plan. Town \& Country Planning organisation in association with Indian Institute of Remote sensing developed the course curriculum for all three Tier purposes. Apart from these, intensive hands on exercise on Formulation of GIS Based Master Plans under AMRUT Sub scheme is being included in the course curriculum to give an in-depth workable knowledge.

These were substantiated by screening films on the subject and group exercises for the participants. The feedback received from these training programmes has been consolidated under the following heads for clarity.

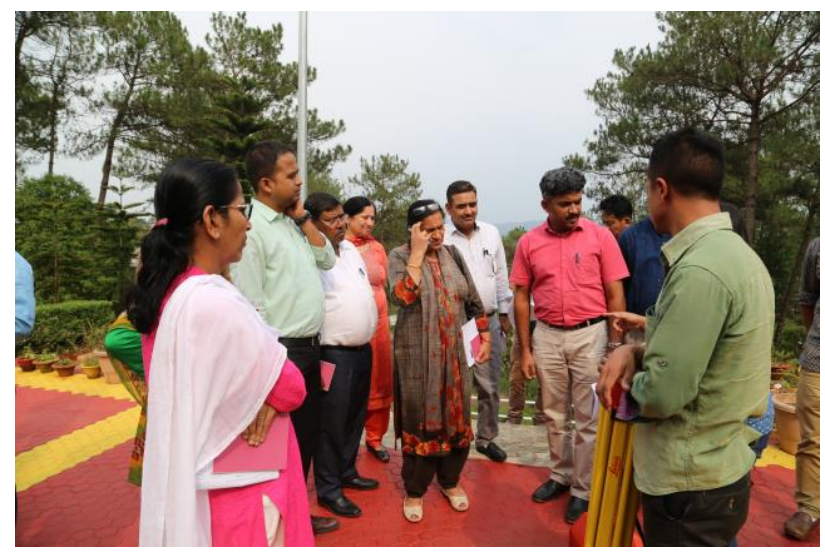

\subsection{Language}

Language is an important consideration while designing a training programme in Indian cities. Unlike the common belief, English may not work in every situation and the local/ regional language is the preferred mode. Hindi works better than English in some states, but a pre-assessment of language requirement goes a long way in increasing the effectiveness of the programme. Since it might not be possible for experts to know all languages, it is also advisable to prepare short and crisp reading materials in the regional language. Inviting local resource people and keeping a good mix of external and local experts help in covering a range of topics.

\subsection{Duration}

Duration of the training programme is an important factor. If the training is organized for Tier 2 \& 3 i.e. Middle level and Junior Level Officers, for example Engineers, Urban Planners, Technical Assistants, data Entry operators, the training was more technical in nature and was planned for a longer duration, 2 weeks and 4 weeks respectively with more emphasis on Hands on training and dedicated sessions for practicals.

While the training programme for Tier 1 group for example Chief town planners, Administrators and Superintendents was compromised on the technicalities, but it focused on broader issues related to the subject and was for shorter duration (3 days) than the one that is designed for a focused group

\subsection{Participants}

Keeping three separate programmes for Tier 1 , Tier $2 \&$ Tier 3 officials turned out to be a good decision because of the clear distinction of roles and responsibilities of the three groups and also the level of understanding of the topic of training.

Participation was observed from many states of India and is illustrated in the following table and the overall female participation rate was 20 percent. 


\begin{tabular}{|l|c|c|c|}
\hline Indian States & \multicolumn{3}{|c|}{ No of participants } \\
\hline Assam & Tier 1 & Tier 2 & Tier 3 \\
Bihar & 2 & 1 & 4 \\
Meghalaya & 11 & 3 & 4 \\
Nagaland & 3 & 5 & \\
Manipur & 1 & & \\
Mizoram & 4 & & \\
Arunachal Pradesh & 1 & 3 & 5 \\
Sikkim & 1 & 2 & \\
Uttar Pradesh & 1 & & \\
Madhya Pradesh & 7 & & \\
Andhra Pradesh & 2 & & 10 \\
Telangana & 1 & & \\
Rajasthan & 2 & 7 & 6 \\
Chandigarh & & 3 & \\
Himachal Pradesh & 1 & 2 & \\
Kerela & 3 & 5 & \\
\hline
\end{tabular}

\section{RESULTS \& DISCUSSIONS}

\subsection{Evaluation of Training Conducted}

The reason for evaluation is to assess the training program and involves collection of information about the activities, characteristics, and outcomes of programs to make judgments about the program, improve program effectiveness, and/or inform decisions about future programming.

The evaluation is the final step of the training management cycle. The results of the training evaluation are reflected in the next phase of training planning to improve future training programs

\subsection{Designing Evaluation Tools}

Various evaluation tools can be selected depending on the purposes and methods of evaluation. For the training programs targeting Administrators, Middle \& Junior level officers, a questionnaire has been prepeared for "Level 1: Reaction"; a pre/post test was conducted for "Level 2: Learning

\subsection{Reactions}

The Training module was found useful and new, and the overall reaction to the training programmes was positive, yet it was suggested that the training modules should give direct examples from the day-to-day functioning.

While the officials were very much interested in knowing about the theme, they wanted sector specific solutions to be presented along with the problems, risks, and vulnerability. It was suggested that there should be avenues for more involvement/interaction of the participants, with their roles in the respective projects being discussed. It was also discussed how their role in the projects could be streamlined towards formulating GIS Based Master plans.

The following charts represent the feedback obtained through the online questionnaire in order to evaluate the effectiveness of the training programme.

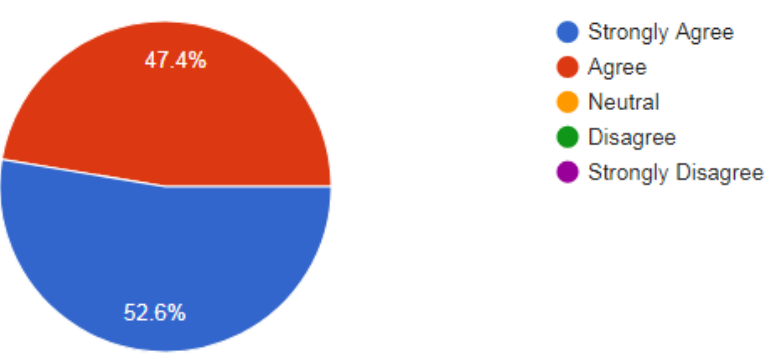

Figure 1: Were the objectives of the training were clearly Defined

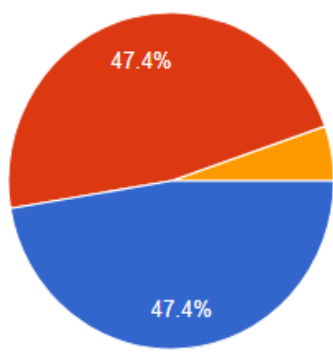

Strongly Agree

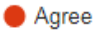

Neutral

Disagree

Strongly Disagree

Figure 2: Was Participation and interaction encouraged

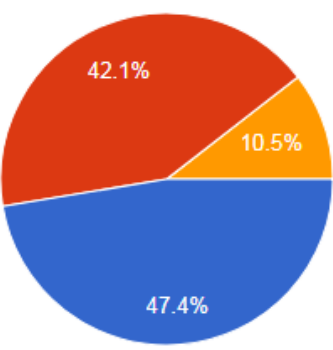

Strongly Agree

Agree

Neutral

Disagree

Strongly Disagree

Figure 3: Were the topics covered relevant

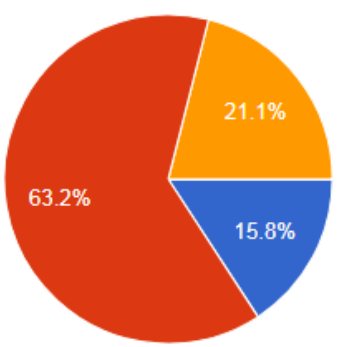

Strongly Agree

Agree

Neutral

Disagree

Strongly Disagree

Figure 4: The content was organised and easy to follow 

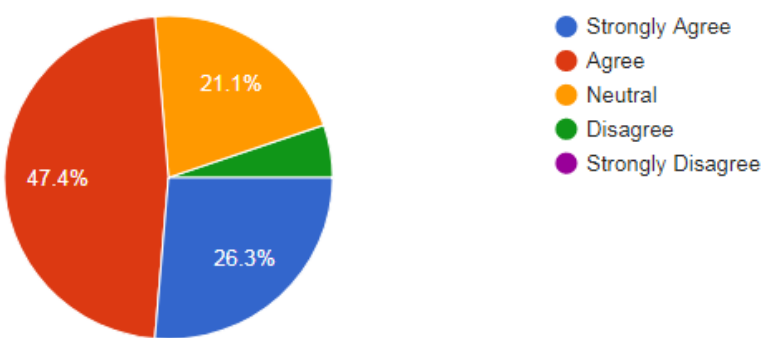

Figure 5: The materials distributed were useful
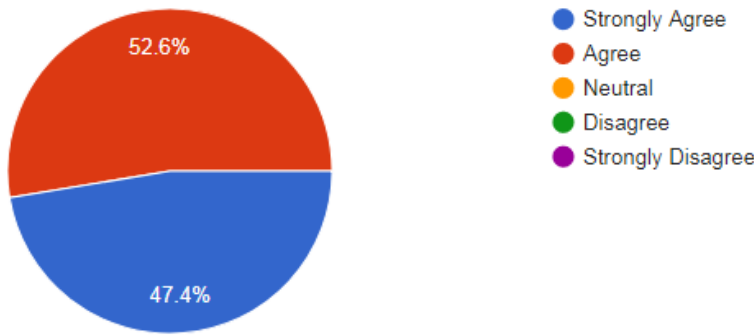

Figure 6: The Training would prove useful in future work
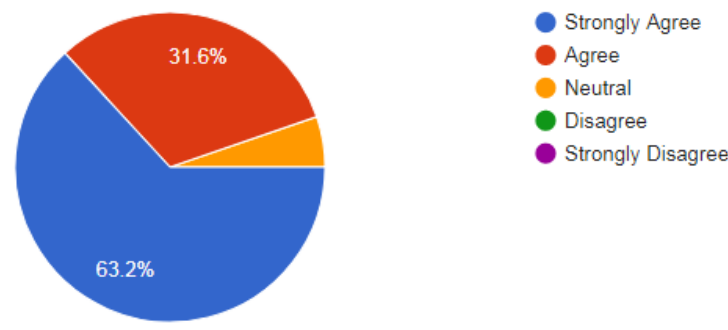

Figure 7: Were the faculty were acquainted about training topics
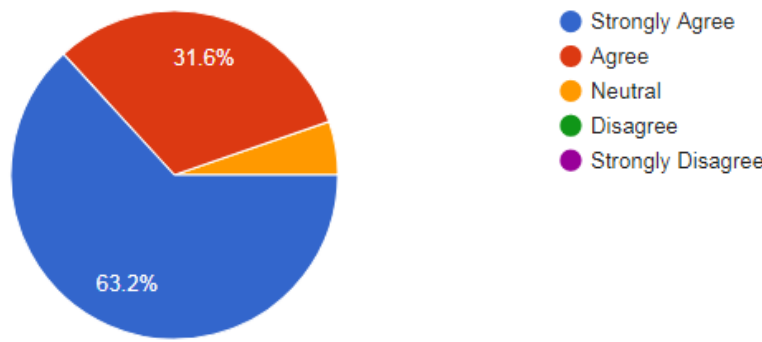

Figure 8: Time allocated for training was sufficient

Besides these, demonstrations to advanced technologies and site visits to projects were suggested to be more effective than classroom teaching. The participants also suggested that sessions should focus on more practical and ground-level implementable solutions such as application of GIS and database management in various components of master plans such as Housing, Landuse, Demography, Infrastructure (Physical \& Social), Environment and transportation. This programme was made open to different planning department heads of local bodies, such as executive engineers, assistant engineers, medical officer for health, staff like junior engineers and staff looking at municipal solid waste (MSW), block level officers, Nagar Parishads, Jal Nigam, electricity department, development authority, PWD and the environment department which was appreciated.

It was suggested that the content of the training programme should be designed to be context specific, for example, adaptation solutions specific to hill states in North Eastern States. It was also suggested by the participants that they would prefer training programmes that equip them best to deal with their day-to-day activities and learn new things in the area of their work. They will be more interested in learning new things if it adds value to their current responsibilities and the training programme is designed, such that they can relate functionally to the subject. So, the modules should be streamlined and aligned to such needs.

\subsection{Conclusions}

The challenges related to capacity of urban local bodies are multiple and have to be addressed at various levels. At the larger level, mandates and mechanisms have to be created that foster an environment of learning and skill building. There should be a planned mechanism to ensure regular training. Besides this, different requirements of different cadre of officials should be assessed and accordingly training programmes should be designed. Issues related to subject matter, new developments, information on the government's new agendas and expectations thereof, have to be addressed through these capacity building programmes.

It is also recommended that capacity building should be the first activity when a new scheme/programme is implemented by the government. Several other new subjects such as energy efficiency, climate change impacts, and disaster management that may not fall directly in the purview of ULBs' functioning have to be covered through standalone programmes, to keep the official abreast of new developments and also to build a cadre of well-informed and skilled ULB officials.

Language barriers, challenges related to scheduling the training programmes and time of the officials could be planned in consultation with the State government. State Training Institutes will have to play a key role in this, while the State and National government have to tap external and institutional expertise, considering the huge volume of capacity building that is required in Indian cities at this juncture. Strategic planned efforts towards a common goal of smart and sustainable Urban Local Bodies will go a long way in building smart and sustainable cities in India.

\section{REFERENCES}

Capacity building for urban development project (CBUD).2014. Conducting Training needs assessment (TNS) \& Preparation of Strategic Training Plan Vol-1 2014. Ministry of Urban development, Govenmnet of India \& World bank.

UNDP.2005. Capacity Building for decentralisation. Ministry of urban development (MoUD), Government of India

Report of the Working Group on Capacity Building 2011. Urban Development management for the formulation of the 
The International Archives of the Photogrammetry, Remote Sensing and Spatial Information Sciences, Volume XLII-5, 2018 ISPRS TC V Mid-term Symposium "Geospatial Technology - Pixel to People", 20-23 November 2018, Dehradun, India

twelfth Five year plan (2012-17), Planning Commission of India.

Capacity Building Project on Disaster Management 2013. Report on Pilot Project (2012-13). Centre for Disaster Management, National Institute of Administrative research \& LBS National Academy of Administration.

Planning Commission of India 2013. Twelfth five year Plan, Volume II (2012-17): Economic sectors. Sage publication pvt ltd 